\title{
Survey on hazardous non-regulated aromatic amines as cleavage products of azo dyes found in clothing textiles on the Swiss market
}

\author{
Stéphanie Crettaz ${ }^{1}$ (1) $\cdot$ Patrick Kämpfer ${ }^{1} \cdot$ Beat J. Brüschweiler ${ }^{2} \cdot$ Susanne Nussbaumer $^{1}$ • \\ Otmar Deflorin ${ }^{1}$
}

Received: 27 March 2019/Revised: 18 July 2019/Accepted: 26 July 2019/Published online: 12 August 2019

(C) The Author(s) 2019

\begin{abstract}
Azo dyes represent the most widely used chemical class of dyes in textiles. They may be biotransformed into aromatic amines by human skin bacteria. These aromatic amines might then enter the body through dermal absorption. Twenty-two aromatic amines are known carcinogens. Therefore, azo dyes are banned for the use in textiles for clothing in the European Union. Non-regulated aromatic amines with suspected toxic properties might also be released by azo dyes. For this survey, 58 aromatic amines of toxicological concern were selected, including the 22 regulated as well as aromatic amines suspected of being mutagenic and some of their positional isomers. Their occurrence and content after the reductive cleavage of the azo bond were investigated in 150 random textile samples from Swiss retail outlets and online shops. Substances suspected of being mutagenic, including potential reduction derivates of nitro compounds were detected in relevant concentrations $(>30 \mathrm{mg} / \mathrm{kg}$ ) in $25 \%$ of the analyzed samples. This survey clearly shows that a substantial percentage of the azo dyes used in today's textiles for cloth are made up of aromatic amines possessing mutagenic and/or other hazardous properties.
\end{abstract}

Keywords Azo dyes · Aromatic amines · Nitro compounds · Textiles · Cloth $\cdot$ Market survey

\section{Introduction}

Azo dyes represent the most widely used chemical class of dyes in textiles (FriedliPartner 2009; Brüschweiler and Merlot 2017). Basically, azo dyes are synthetized from aromatic amines (AAs) by diazotation and are characterized by one or several azo groups (Platzek et al. 1999). Several studies have shown the ability of skin bacteria to reductively cleave the azo bonds of azo dyes, releasing AAs, which may then be absorbed through the skin (Platzek et al. 1999; Stingley et al. 2010). Workers can also be exposed to these substances during the dying process of textiles, and the formation of AAs by degradation of azo

Stéphanie Crettaz

stephanie.crettaz@gef.be.ch

1 Official Food Control Authority of the Canton of Berne, Muesmattstrasse 19, 3012 Bern, Switzerland

2 Federal Food Safety and Veterinary Office (FSVO), Schwarzenburgstrasse 155, 3003 Bern, Switzerland dyes has been shown to cause environmental pollution (Brüschweiler and Merlot 2017; Rawat et al. 2016).

In the European Union, 22 of these AAs are classified as carcinogen category. $1 \mathrm{~A}$ or $1 \mathrm{~B}$ (and some as mutagen category. $1 \mathrm{~B}$ or 2) in the CLP Regulation (EC) No $1272 / 2000$ and banned for use in azo dyes in textiles and leather articles for direct and prolonged skin contact. These AAs are listed in Appendix 8 of the $\mathrm{REACH}$ regulation (EC) No 1907/2006. According to REACH Annex XVII entry 43, azo dyes which, are cleaved off of one or more azo groups, may release one or more of the AAs listed in Appendix 8 in detectable concentration, i.e., above $30 \mathrm{mg} /$ $\mathrm{kg}$ in the article according to defined testing methods, shall not be used (EC 2006). The methods to determine these AAs, which derive from azo colorants in textiles, are defined in the standards DIN EN 14362-1 and DIN EN 14362-3 (DIN 2017a, b). In Switzerland, the regulation of these compounds in clothing textiles is harmonized with the European Union (FDHA 2005, SR 817.023.41).

Friedlipartner (2009) inventoried dyes from different data sources leading to a database with 1980 dyes 
potentially used in textiles, including 896 azo dyes. Half of these identified azo dyes are parent compounds that can be potentially cleaved into one of the 22 well known regulated carcinogenic amines. The other half can generate other non-regulated AAs by reductive cleavage. Brüschweiler et al. (2014) prioritized these AAs based on their toxicity. Twenty-nine toxic AAs (including potentially carcinogenic and/or genotoxic substances and substances which may cause sensitization by skin contact) could be identified. Because of the analytical method limitations, only 22 of these AAs could be determined. They collected 153 samples of clothing in the Canton of Berne in Switzerland and classified 44 substances as high priority to analyze in these textiles, including the 22 amines regulated in REACH. Eight different non-regulated toxic AAs were detected in $17 \%$ of the samples (Brüschweiler et al. 2014).

Brüschweiler and Merlot (2017) identified 40 mutagenic AAs as potential reduction products of approximately 180 different azo dyes used in clothing textiles. Based on those studies, a list of 71 hazardous AAs as cleavage products of azo dyes from textiles was compiled. The aim of this study was to evaluate if the 71 AAs of interest are products of reductive cleavage of azo dyes used in textiles on the Swiss market.

\section{Materials and methods}

\subsection{Samples}

We purchased 150 samples of colored or black clothing between March and April 2018 in the Canton of Berne in Switzerland. Several types of garments were sampled: socks, underwear, T-shirts, children's clothing and sports clothing. Only articles for direct skin contact were selected. The sampling focused on mainstream shops and brands with affordable prices; the purpose was to constitute a sample of clothing worn by a majority of people. Luxury brands as well as second hand articles were not considered.

We collected 126 samples in shops from 17 different retailers. Twenty-four samples were ordered online. The sampling encompassed at least 65 different brands. The number of collected samples per clothing category and country of production are shown in Table 1 .

Regarding the fiber composition of the samples, cotton, polyester, and polyamide were the most frequent, either as individual components or as the main proportion of blends (from $50 \%$ of the textile composition). Some collected samples contained mostly viscose, micromodal and merino wool. Elastane was present as a small component (5-30\%) in $50 \%$ of the samples. Table 2 gives an overview of the collected samples with regard to their color and textile fiber.

\subsection{Analysis of the samples}

Kämpfer et al. (2019) described the applied analytical method including chemicals and reagents, instrumental parameters and qualitative and quantitative performance of the method in detail. The developed method allowed the simultaneous quantification of 58 AAs, including the 22 EU-regulated compounds, other non-regulated toxic substances and some of their isomers, in clothing textiles with satisfying method performance. The samples were prepared according to the standard DIN EN 14362-1: 2017 (DIN 2017a) with modifications. Because of the wide polarity spectrum of the amines, the sample clean-up with diatomaceous earth column could not be applied. This omission was compensated by the high sensitivity of the instrument.

The sample workup started by cutting the textiles into small pieces. In case of synthetic fibers, an additional step was necessary in order to extract potentially present disperse dyes, because they are not accessible to reduction if they are bound to the fiber. Therefore, polyester fibers as well as some polyamide and acrylic fibers have been extracted with xylene first (DIN EN 14362-1:2017). After the evaporation of xylene, these samples were further treated like all other samples. The samples were incubated in citrate buffer at $\mathrm{pH} 6$ and sodium dithionite was added in order to reductively cleave potentially present azo dyes, releasing the AAs. The analyses were then carried out on a Shimadzu Nexera HPLC system (Reinach BL, Switzerland) coupled with a QTrap6500 + hybride triple-quadrupole-ion Trap mass spectrometer from Sciex (Baden, Switzerland). The AAs in the diluted reduction solutions were chromatographically separated with a biphenyl column and quantified on two independent fragment transitions in MRM (multiple reaction monitoring) mode. In order to verify the identity of the substances, enhanced product ion (EPI) spectra were recorded and compared with an in house-built spectra library. For multicolored samples, each color was examined individually. If there was a positive finding ( $>5 \mathrm{mg} / \mathrm{kg}$ ), a confirmation analysis was performed.

\subsection{Traceability}

The traceability of textile dyes was investigated. Therefore, 13 companies were randomly selected and asked for supplementary documents corresponding to 33 selected samples with positive findings. The following information concerning the used dyes was requested: Chemical Abstract Service (CAS) number, Colour Index (C.I.) name, C.I. number and other relevant information, if available. The obtained information was used to identify the structure of the dyes, and compared with the results of the analyses. Chemical structure 
Table 1 Number of collected samples: clothing category as function of the country of production

\begin{tabular}{|c|c|c|c|c|c|c|c|c|}
\hline \multirow[t]{2}{*}{ Types of cloths } & \multicolumn{8}{|c|}{ Country of production } \\
\hline & China (n) & Bangladesh (n) & Turkey (n) & India (n) & Indonesia (n) & Other (n) & Unknown (n) & Total (n) \\
\hline Socks & 3 & 0 & 6 & 0 & 1 & 9 & 7 & 26 \\
\hline Underwear & 11 & 1 & 0 & 0 & 2 & 7 & 9 & 30 \\
\hline T-shirts & 5 & 16 & 1 & 5 & 0 & 10 & 3 & 40 \\
\hline Children's clothing & 4 & 7 & 1 & 3 & 2 & 5 & 5 & 27 \\
\hline Sportswear & 12 & 2 & 2 & 0 & 1 & 9 & 1 & 27 \\
\hline Total & 35 & 26 & 10 & 8 & 6 & 40 & 25 & 150 \\
\hline
\end{tabular}

Table 2 Number of collected samples: color as function of the type of textile fiber (defined as the main proportion, from $50 \%$ of the blend)

\begin{tabular}{lrrrllllll}
\hline Color & \multicolumn{2}{l}{ Type of textile fibers } \\
\cline { 2 - 9 } & Cotton & Polyester & Polyamide & Viscose & Micro-Modal & Acrylic & Wool & Unknown & Total \\
\hline Black & 27 & 10 & 10 & 4 & 2 & 0 & 0 & 0 & 53 \\
Blue & 18 & 6 & 4 & 1 & 0 & 0 & 1 & 1 & 31 \\
Red & 19 & 11 & 3 & 1 & 1 & 0 & 0 & 1 & 36 \\
Orange & 2 & 4 & 1 & 0 & 0 & 1 & 0 & 0 & 8 \\
Yellow & 5 & 1 & 0 & 0 & 0 & 0 & 0 & 0 & 6 \\
Purple & 2 & 1 & 0 & 0 & 0 & 0 & 0 & 0 & 3 \\
Green & 9 & 2 & 2 & 0 & 0 & 0 & 0 & 0 & 13 \\
Total & 82 & 35 & 20 & 6 & 3 & 1 & 1 & 2 & 150 \\
\hline
\end{tabular}

search was done on the European Chemicals Agency (ECHA 2018) registered substances database using the CAS numbers or C.I. names provided on the documents. When there was no match with the ECHA database, the search was repeated on other chemical databases (www.chemnet.com, www.chemicalbook.com, www.molbase.com, www.bocsi. com, www.worlddyevariety.com, www.lookchem.com; accessed 15 December 2018).

From 13 contacted companies, 11 feedbacks were provided. For 10 samples, it was not possible to get the requested information, either due to trade secret, or to a difficult access to information from suppliers. For some samples, the information was incomplete. Finally, complete information about dyestuff could only be collected for six cotton samples, one polyester sample and one wool sample. However, some of the received information on dyestuff was not consistent with our analytical results.

\section{Results and discussion}

\subsection{Selection and analysis of AAs}

Originally, it was planned to analyze 71 AAs of interest, based on different published sources (22 from REACH, annex XVII, Appendix 8; 8 from Brüschweiler et al. 2014; 41 from Brüschweiler and Merlot 2017). However, some substances could not be analyzed due to stability or analytical issues. 1,2,4-Triaminobenzene (CAS 615-47-4) and 1,4-naphthalenediamine (CAS 2243-61-0) could not be followed up in this study due to stability issues. 4-Aminoazobenzene (CAS 60-09-3) and $o$-aminoazotoluene (CAS 97-56-3) listed in REACH Appendix 8 were indirectly determined by their reaction products (aniline and $p$ phenylenediamine, as well as o-toluidine and 2,5-diaminotoluene) according to EN 14362-1 (DIN 2017a). Eighteen AAs contained a nitro moiety. These substances are either completely decomposed or reduced to the corresponding amines during the sample treatment with dithionite. Eight of these amines could be detected via their derived products. Five of the derived products were already present in the list of the AAs, the three others were included in the list. The other 10 nitro compounds could not be determined after reduction.

The chromatographic separation and the specific detection of AAs is a challenging task. The separation of isomeric compounds can be problematic. Ten additional isomers were integrated in the method in order to check the specificity. Except 2,4-diaminoanisole (CAS 615-05-4) and 2,5-diaminoanisole (CAS 5307-02-8), all isomers were separated. Another issue was the determination of 1,2,4,5benzenetetramine (CAS 3204-61-3) and 4,6-diaminoresorcinol (CAS 16523-31-2). Both deliver the same product ions and could not be chromatographically separated. 
Finally, 58 AAs could be quantified with the method. Method performance including limit of quantification and measurement uncertainty were published elsewhere (Kämpfer et al. 2019). In Table 3, the 71 AAS of interest and the 13 AAs integrated in the method for analytical reasons are enumerated with their corresponding CAS number, name, analytical issues, and toxicology references.

\subsection{Positive findings of AAs}

An overview of all detected AAs in the textile samples with their concentration levels and frequency is shown in Table 4.

Many positive samples contained one or two different amines. In five samples three or four different AAs were detected. The analysis of a black T-Shirt for kids (polyester/elastane mixture) showed positive finding for seven amines, including aniline and p-phenylenediamine. These two AAs can occur as reduction products of 4-aminoazobenzene, which is listed in REACH Appendix 8. In order to confirm the presence of 4-aminoazobenzene, the method according to DIN EN 14362-3:2017 was used. A release of $652 \mathrm{mg} / \mathrm{kg}$ was measured in the sample. The article was removed from the market by order of the competent authority. In the same sample, $p$-aminophenol, 2,4-diaminobenzenesulfonic acid, 4-chloro-1,2-diaminobenzene, 2,6-dichloro-1,4-benzenediamine and $N, N$-diethyl-3methyl-1,4-phenylenediamine were also detected in concentrations ranging from 70 to $800 \mathrm{mg} / \mathrm{kg}$.

2,4-Diaminotoluene, also regulated in $\mathrm{REACH}$, was found in two black bras made of polyester and polyamide blend. However, the detected quantities were below $30 \mathrm{mg} /$ $\mathrm{kg}$.

From the analyzed compounds, 20 AAs were present in at least one sample and 38 compounds haven't been detected. $p$-Aminobenzenesulfonic acid, $o$-aminobenzenesulfonic acid and $p$-phenylenediamine were the most abundant compounds with a total number of respectively 37,19 and 17 positive findings.

Non-regulated AAs could be quantified in 72 of the 150 examined samples (48\%) (Fig. 1). In 60 samples (40\%) the measured content of individual AAs was $>30 \mathrm{mg} / \mathrm{kg}$. Substances suspected of being mutagenic as reported by Brüschweiler and Merlot (2017), including the potential reduction derivates of nitro compounds, were detected in relevant concentrations ( $>30 \mathrm{mg} / \mathrm{kg}$ ) in 37 samples $(25 \%)$. The number of positive findings of these suspected toxic compounds in different fiber types is presented in Fig. 2. In $46 \%$ of all polyester textile samples, toxic substances were found in concentrations $>30 \mathrm{mg} / \mathrm{kg}$. The percentage was lower for cellulose based fiber samples $(17 \%)$ and polyamide (20\%).
The concentrations of detected non-regulated AAs are shown in Fig. 3. A red top contained $3491 \mathrm{mg} / \mathrm{kg}$ of $o$ aminobenzenesulfonic acid. This was the highest content measured in this survey. The other concentrations ranged between 5 and $1238 \mathrm{mg} / \mathrm{kg}$.

\section{3 p-Phenylenediamine and other potential derivates of nitro compounds}

$p$-Phenylenediamine is suspected of being mutagenic (Brüschweiler and Merlot 2017; CCRIS) and a well-known skin sensitizer (C\&L inventory, ECHA). It was detected in relevant concentrations $(>30 \mathrm{mg} / \mathrm{kg}$ ) in nine samples with major polyester content $(67-953 \mathrm{mg} / \mathrm{kg})$ and in three polyamide samples $(70-601 \mathrm{mg} / \mathrm{kg})$. The mean concentration of dyes in garments is $3.5 \%$ for dark colors (BGFA 2009). The measured concentrations of $p$-phenylenediamine in this survey amount between 67 and $953 \mathrm{mg} / \mathrm{kg}$. These values correspond to 0.2 and $2.7 \%$ of the theoretical mean dye load on garment.

In a study performed in 2014 by the French Agency for Food, Environmental and Occupational Health and Safety (ANSES) on 25 clothing samples, $p$-phenylenediamine was found in four dark polyester samples (ANSES 2018). However, the reported concentrations (13-56 mg/kg) were lower than in our study. The methodology used in the ANSES study implied a clean-up step with a diatomaceous earth column, according to DIN EN 14362-1:2017. This may lead to lower recoveries for some AAs, like for p-phenylenediamine than with our method. $p$-Phenylenediamine may also result from the reduction of 4-nitroaniline (CAS 100-01-6). With the used method, it is not possible to distinguish whether the nitro compound or $p$ phenylenediamine itself was present in the textile.

Three further potential reduction derivates of nitro compounds, 4-chloro-1,2-diaminobenzene, 2-chloro-1,4diaminobenzene and 2,6-dichloro-1,4-benzenediamine, were quantified in relevant concentrations in five, five and three of the tested polyester samples, respectively. 4-Chloro-1,2-diaminobenzene and 2,6-dichloro-1,4-benzenediamine are suspected of causing cancer according to C\&L inventory (Carc. $2 \mathrm{H} 351$ ). As for 4-nitroaniline, the nitro compounds corresponding to the previously mentioned amines (2-nitro-4-chloroaniline, 2-chloro-4-nitroaniline, 2,6-dichloro-4-nitroaniline) are suspected of being mutagenic (Brüschweiler and Merlot 2017). In a red polyester bra, 4-chlor-1,2-diaminobenzene (the reduction product of 2-nitro-4-chloroaniline, CAS 89-63-4) was found at a concentration of $64 \mathrm{mg} / \mathrm{kg}$. In this case, the presence of 2-nitro-4-chloroaniline in the sample was confirmed by the information about the applied dyes provided by the company. 
Table 371 AAs of toxicological interest, 10 positional isomers and 3 reduction derivates

\begin{tabular}{|c|c|c|c|}
\hline CAS & Name & Analytical issues & $\begin{array}{l}\text { Toxicology } \\
\text { reference }\end{array}$ \\
\hline $60-09-3$ & 4-Aminoazobenzene & $\begin{array}{l}\text { Reduced to aniline (CAS 62-53-3) and } \\
\text { p-phenylenediamine (CAS 106-50-3) }\end{array}$ & A \\
\hline $97-56-3$ & $o$-Aminoazotoluene & $\begin{array}{l}\text { Reduced to o-toluidine (CAS 95-53-4) und 2,5- } \\
\text { diaminotoluene (CAS 95-70-5) }\end{array}$ & A \\
\hline $88-21-1$ & $o$-Aminobenzenesulfonic acid & & B \\
\hline $121-57-3$ & $p$-Aminobenzenesulfonic acid & & $\mathrm{C}$ \\
\hline $121-47-1$ & $m$-Aminobenzenesulfonic acid & & $\mathrm{D}$ \\
\hline $92-67-1$ & 4-Aminobiphenyl & & A \\
\hline $88-53-9$ & 4-Amino-5-chloro-2-methylbenzenesulfonic acid & & $\mathrm{C}$ \\
\hline $1747-60-0$ & 2-Amino-6-methoxybenzothiazol & & B \\
\hline $123-30-8$ & $p$-Aminophenol & & B \\
\hline $122-80-5$ & $p$-Aminoacetanilide & & B \\
\hline $95-85-2$ & 2-Amino-4-chlorophenol & & B \\
\hline $95-84-1$ & 2-Amino-4-methylphenol & & B \\
\hline $62-53-3$ & Aniline & & $\mathrm{B}$ \\
\hline $90-04-0$ & $o$-Anisidine & & A \\
\hline 104-94-9 & $p$-Anisidine & & B \\
\hline $3204-61-3$ & 1,2,4,5-Benzenetetramine & $\begin{array}{l}\text { Same product ions as } 4,6 \text {-diaminoresorcinol and } \\
\text { retention time; cannot be separated }\end{array}$ & B \\
\hline 2050-89-7 & 3,3'-Benzidine & & $\mathrm{D}$ \\
\hline $92-87-5$ & 4,4'-Benzidine & & A \\
\hline $3282-99-3$ & 1,1-bis(4-Aminophenyl)-cyclohexane & & B \\
\hline $108-42-9$ & $m$-Chloroaniline & & $\mathrm{D}$ \\
\hline $95-51-2$ & $o$-Chloroaniline & & $\mathrm{C}$ \\
\hline $106-47-8$ & $p$-Chloroaniline & & A \\
\hline $95-83-0$ & 4-Chloro-1,2-diaminobenzene & & $\mathrm{E}$ \\
\hline $615-66-7$ & 2-Chloro-1,4-diaminobenzene & & $\mathrm{E}$ \\
\hline $121-87-9$ & 2-Chloro-4-nitroaniline & $\begin{array}{l}\text { Detectable as 2-chloro-1,4-diaminobenzene (CAS } \\
615-66-7 \text { ) }\end{array}$ & B \\
\hline $95-69-2$ & 4-Chloro-o-toluidine & & A \\
\hline $120-71-8$ & $p$-Cresidine & & A \\
\hline $88-63-1$ & 2,4-Diaminobenzenesulfonic acid & & $\mathrm{C}$ \\
\hline 19471-12-6 & 3,3'-Diaminodiphenylmethane & & $\mathrm{D}$ \\
\hline $101-77-9$ & 4,4'-diaminodiphenylmethane & & A \\
\hline $95-80-7$ & 2,4-Diaminotoluene & & A \\
\hline $95-70-5$ & 2,5-Diaminotoluene & & B \\
\hline $823-40-5$ & 2,6-Diaminotoluene & & $\mathrm{D}$ \\
\hline $496-72-0$ & 3,4-Diaminotoluene & & $\mathrm{D}$ \\
\hline $615-05-4$ & 2,4-Diaminoanisol & Positional isomers; cannot be separated & A \\
\hline $5307-02-8$ & 2,5-Diaminoanisol & & $\mathrm{B}$ \\
\hline $102-51-2$ & 3,4-Diaminoanisol & & $\mathrm{D}$ \\
\hline $16523-31-2$ & 4,6-Diaminoresorcinol & $\begin{array}{l}\text { Same product ions as } 1,2,4,5 \text {-benzenetetramine and } \\
\text { retention time; cannot be separated }\end{array}$ & B \\
\hline $2051-79-8$ & $N, N$-Diethyl-3-methyl-1,4-Phenylenediamine & & $\mathrm{C}$ \\
\hline $95-68-1$ & 2,4-Dimethylaniline & & B \\
\hline $95-78-3$ & 2,5-Dimethylaniline & & $\mathrm{D}$ \\
\hline $87-62-7$ & 2,6-Dimethylaniline & & B \\
\hline $84-67-3$ & 2,2'-Dimethylbenzidine & & B \\
\hline
\end{tabular}


Table 3 (continued)

\begin{tabular}{|c|c|c|c|}
\hline CAS & Name & Analytical issues & $\begin{array}{l}\text { Toxicology } \\
\text { reference }\end{array}$ \\
\hline $119-93-7$ & 3,3'-Dimethylbenzidine & & A \\
\hline $119-90-4$ & 3,3'-Dimethoxybenzidine & & A \\
\hline $838-88-0$ & 3,3-Dimethyl-4,4-diaminodiphenylmethane & & A \\
\hline $95-76-1$ & 3,4-Dichloroaniline & & $\mathrm{C}$ \\
\hline $91-94-1$ & 3,3'-Dichlorobenzidine & & A \\
\hline $609-20-1$ & 2,6-Dichloro-1,4-benzenediamine & & E \\
\hline $99-30-9$ & 2,6-Dichloro-4-nitroaniline & $\begin{array}{l}\text { Detectable as 2,6-dichloro-1,4-phenylenediamine (CAS } \\
609-20-1 \text { ) }\end{array}$ & B \\
\hline $93-05-0$ & $N, N$-Diethyl- $p$-phenylenediamine & & B \\
\hline $99-98-9$ & $N, N$-Dimethyl- $p$-phenylenediamine & & B \\
\hline $6393-01-7$ & 2,5-Dimethyl-1,4-benzenediamine & & $\mathrm{B}$ \\
\hline $156-43-4$ & 4-Ethoxyaniline & & B \\
\hline $91-59-8$ & 2-Naphthylamine & & A \\
\hline $97-52-9$ & 2-Methoxy-4-nitroaniline & Detectable as 2,5-diaminoanisol (CAS 5307-02-8) & $\mathrm{B}$ \\
\hline $99-59-2$ & 2-Methoxy-5-nitroaniline & Detectable as 2,4-diaminoanisol (CAS 615-05-4) & $\mathrm{B}$ \\
\hline $99-55-8$ & 2-Methyl-5-nitroaniline & Detectable as 2,4-diaminotoluene (CAS 95-80-7) & A \\
\hline $101-14-4$ & 4,4-Methylen-bis(2-chloroaniline) & & A \\
\hline $99-09-2$ & 3-Nitroaniline & Detectable as m-phenylenediamine (CAS 108-45-2) & $\mathrm{B}$ \\
\hline $100-01-6$ & 4-Nitroaniline & Detectableas p-phenylenediamine (CAS 106-50-3) & $\mathrm{B}$ \\
\hline $89-63-4$ & 2-Nitro-4-chloroaniline & $\begin{array}{l}\text { Detectable as 4-chloro-1,2-diaminobenzene (CAS } \\
95-83-0)\end{array}$ & $\mathrm{B}$ \\
\hline $101-80-4$ & 4,4'-Oxydianiline & & A \\
\hline $108-45-2$ & $m$-Phenylenediamine & & $\mathrm{B}$ \\
\hline $106-50-3$ & $p$-Phenylenediamine & & $\mathrm{B}$ \\
\hline $101-54-2$ & $N$-Phenyl- $p$-phenylenediamine & & $\mathrm{C}$ \\
\hline $139-65-1$ & 4,4'-Thiodianiline & & A \\
\hline $108-44-1$ & $m$-Toluidine & & $\mathrm{D}$ \\
\hline $95-53-4$ & $o$-Toluidine & & A \\
\hline $106-49-0$ & $p$-Toluidine & & $\mathrm{C}$ \\
\hline $137-17-7$ & 2,4,5-Trimethylaniline & & A \\
\hline $88-05-1$ & 2,4,6-Trimethylaniline & & $\mathrm{D}$ \\
\hline 2243-61-0 & 1,4-Naphthalenediamine & Unstable & B \\
\hline $615-47-4$ & 1,2,4-Triaminobenzene & Unstable & $\mathrm{B}$ \\
\hline 14346-19-1 & 3-Amino-5-nitro-2,1-benzisothiazol & Decomposition/no reduction product detectable & $\mathrm{B}$ \\
\hline $121-66-4$ & 2-Amino-5-nitrothiazol & Decomposition/no reduction product detectable & $\mathrm{B}$ \\
\hline $1817-73-8$ & 2-Bromo-4,6-dinitroaniline & Decomposition/no reduction product detectable & $\mathrm{B}$ \\
\hline $3531-19-9$ & 6-Chloro-2,4-dinitroaniline & Decomposition/no reduction product detectable & $\mathrm{B}$ \\
\hline $6285-57-0$ & 2-Amino-6-nitrobenzothiazol & Decomposition/no reduction product detectable & $\mathrm{B}$ \\
\hline $96-91-3$ & 4,6-Dinitro-2-aminophenol & Decomposition/no reduction product detectable & $\mathrm{B}$ \\
\hline $97-02-9$ & 2,4-Dinitroaniline & Decomposition/no reduction product detectable & $\mathrm{B}$ \\
\hline $121-88-0$ & 2-Hydroxy-4-nitroaniline & Decomposition/no reduction product detectable & B \\
\hline $99-57-0$ & 2-Hydroxy-5-nitroaniline & Decomposition/no reduction product detectable & $\mathrm{B}$ \\
\hline $5131-58-8$ & 4-Nitro-1,3-phenylenediamine & Decomposition/no reduction product detectable & B \\
\hline
\end{tabular}

Toxicology reference: (A) REACH, Annex XVII, Append. 8, (B) Brüschweiler and Merlot (2017), (C) Brüschweiler et al. (2014), (D) positional isomers and $(\mathrm{E})$ reduction derivates 


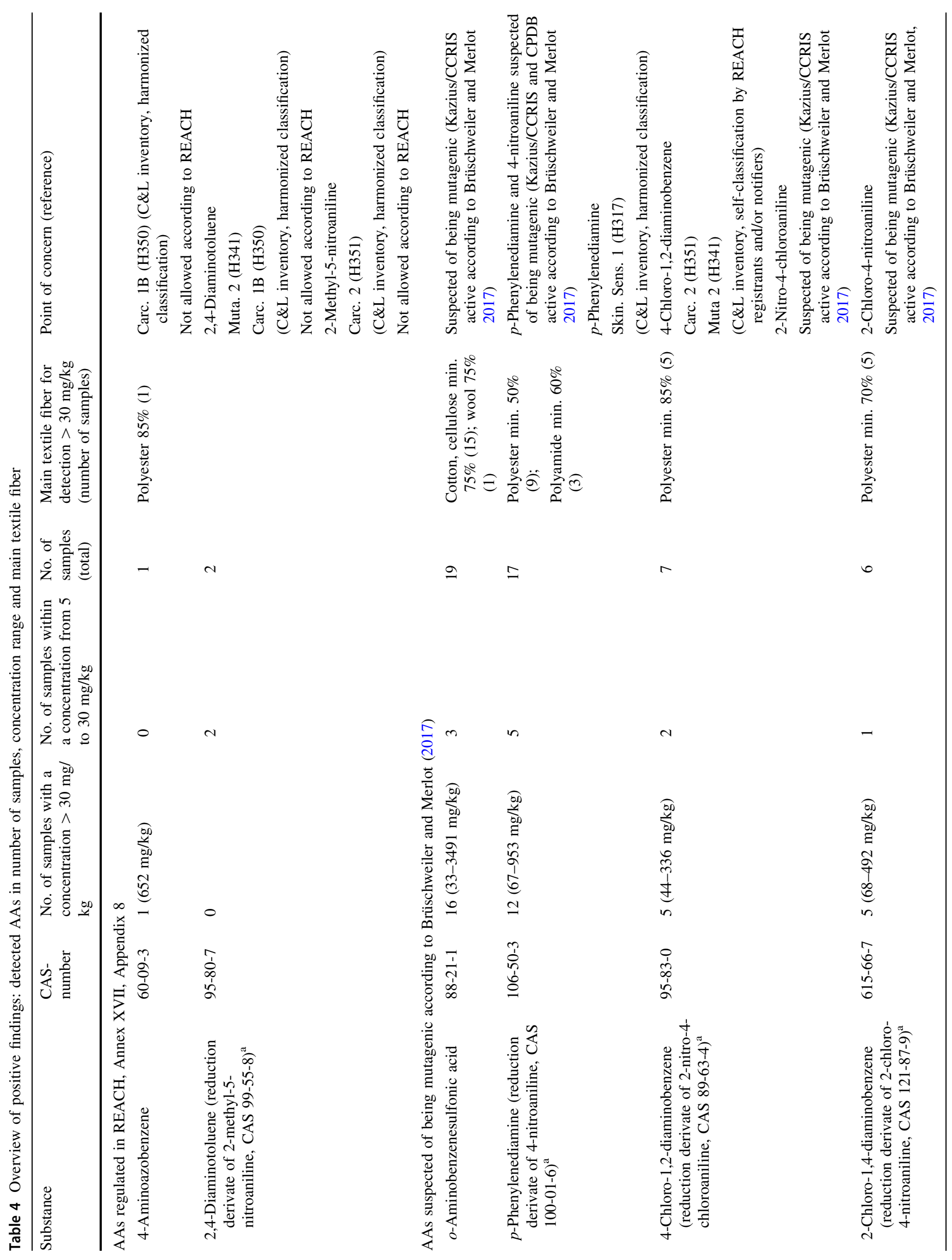




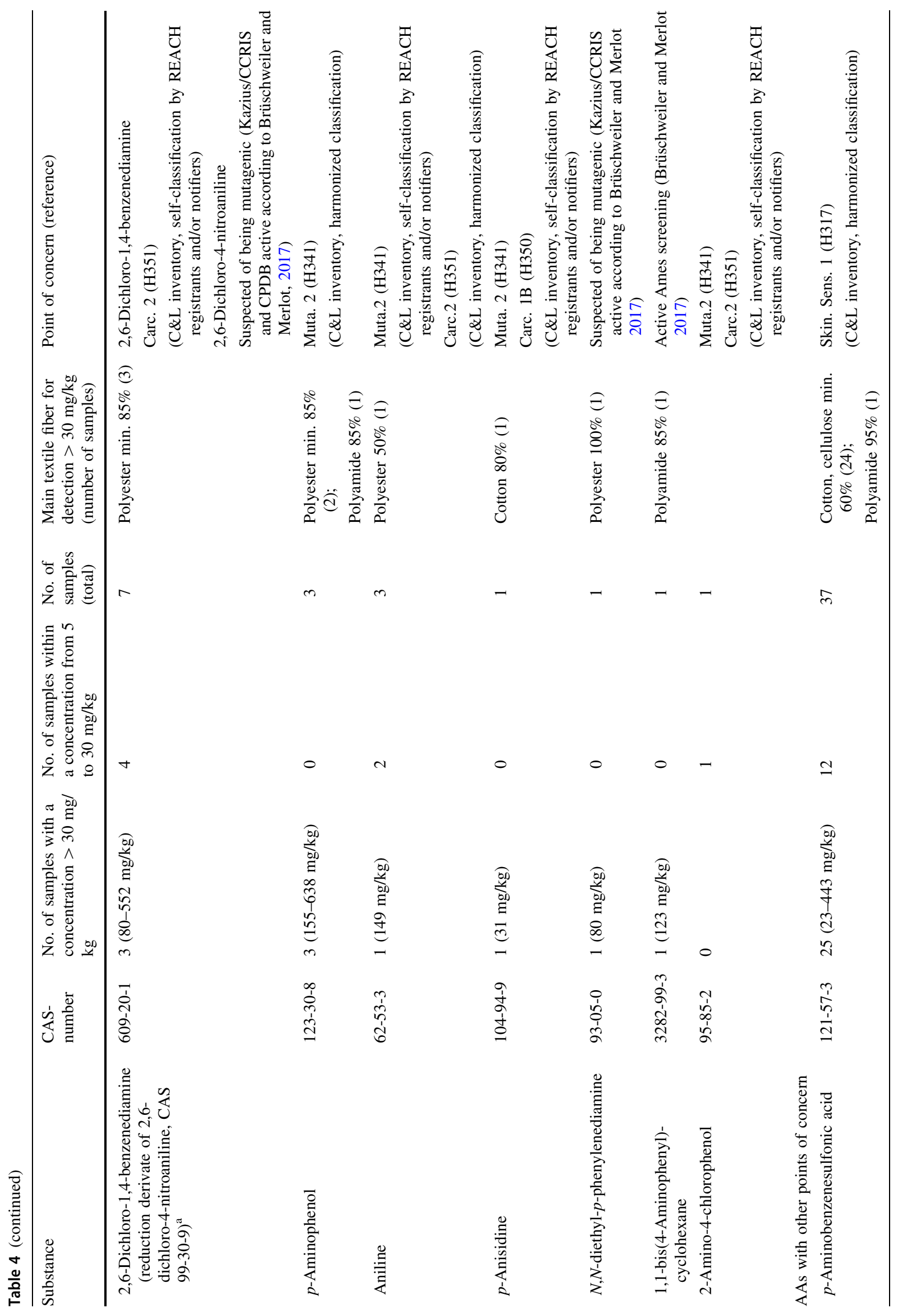




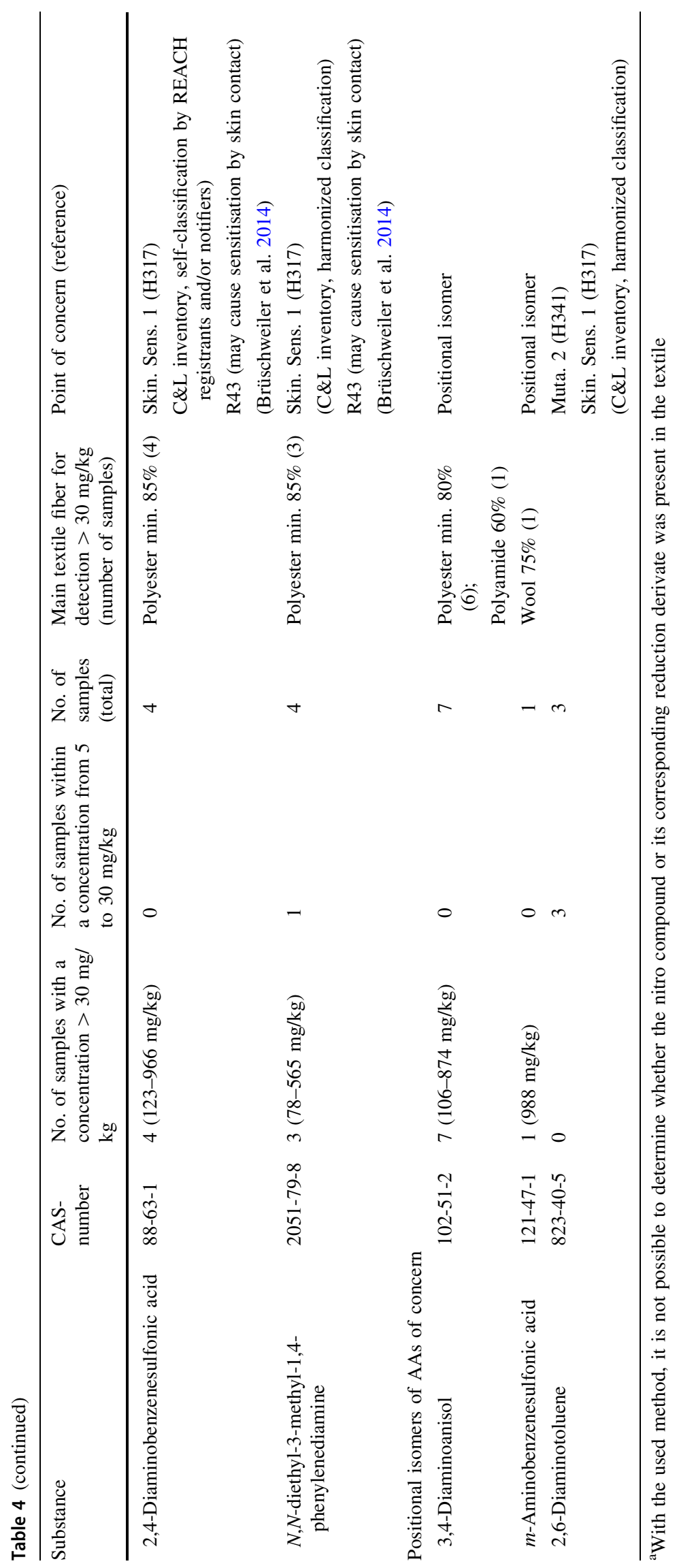




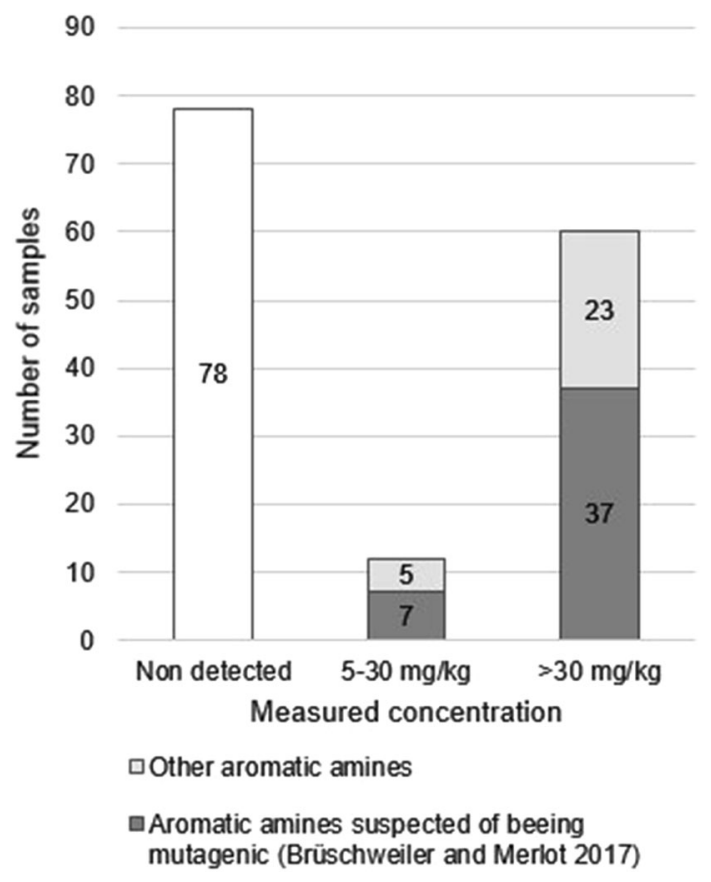

Fig. 1 Number of samples per measured concentration of nonregulated AAs; AAs suspected of being mutagenic by Brüschweiler and Merlot (2017) are highlighted

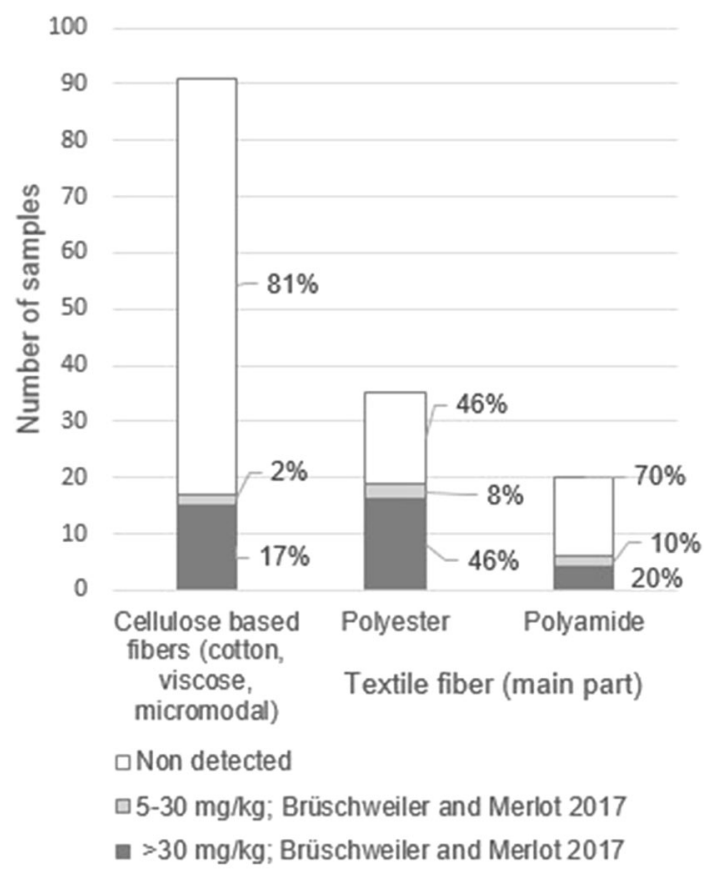

Fig. 2 Number of positive samples with respect to non-regulated AAs suspected of being mutagenic by Brüschweiler and Merlot (2017) as function of the fiber type (main part of blends, from 50\%)

The information provided by the supplier regarding the only wool sample of the study allowed the identification of 4,6-dinitro-2-aminophenol (CAS 96-91-3) as a constituent of one used azo dye. This substance is suspected of being mutagenic (Brüschweiler and Merlot 2017). Unfortunately, it could not be analyzed in this study due to the instability of its reduction product.

Disperse dyes contain hydrophobic groups, like $-\mathrm{NO}_{2}$, but no ionic functions. Due to their lipophilic properties, dispersed dyes are particularly suitable for the dying of hydrophobic fibers like polyester (BGFA 2009). Therefore, it would be more plausible that nitro compounds are present in polyester, rather than their amino derivates, for textiles that were dyed with the use of state-of-the-art technology. Several studies have indicated that nitro compounds might be frequently used in textiles, particularly in polyester. ANSES (2018) reported about three studies carried out in France between 2013 and 2015 on clothing textiles, sport articles and children's textiles. According to these studies, halogenated and nitro group containing AAs are regularly found in dark polyester, among others, 2,6-dichloro-4-nitroaniline. One of the studies mentioned free AAs with nitro moieties in concentrations above $100 \mathrm{mg} / \mathrm{kg}$ in dark polyester samples. The method used for these analyses probably did not involve a reduction step. According to Hunger (2003) 4-nitroaniline and some of its halogenated and nitro substituted derivates (including 2,6-dichloro-4-nitroaniline) are important components in commercial disperse azo dyes. These findings from the literature suggest, that the previously mentioned substances found in this survey might actually be reduction products of nitro compounds. The reduction derivate of 2,6-dichloro-4-nitroaniline, 2,6dichloro-1,4-benzenediamine, was quantified in relevant concentrations in three samples in this survey.

\subsection{0 - and $p$-Aminobenzenesulfonic acid}

$o$-Aminobenzenesulfonic acid (CAS 88-21-1) is suspected of being mutagenic (Brüschweiler and Merlot 2017). It was quantified in relevant concentrations in 16 samples (33-3491 mg/kg), principally in textiles with a main part of cotton and other cellulose based fibers. $o$-Aminobenzenesulfonic acid was also quantified in the wool sample (231 mg/kg), together with $m$-aminobenzenesulfonic acid $(988 \mathrm{mg} / \mathrm{kg})$. The information provided from the companies confirmed the presence of o-aminobenzenesulfonic acid as a component of reactive azo dyes in two samples of cotton (with measured concentrations of 681 and $3491 \mathrm{mg}$ / $\mathrm{kg}$ ) and in the wool sample $(231 \mathrm{mg} / \mathrm{kg})$. However, the compound was not possible to trace in two black cotton samples (measured concentrations of 1164 and $765 \mathrm{mg} /$ $\mathrm{kg}$ ), for which full information regarding dyestuffs was provided. We hypothesize that:

1. the provided information may have been incomplete or inconsistent, 
Fig. 3 Measured concentrations of AAs in positive samples $(>5 \mathrm{mg} / \mathrm{kg})$

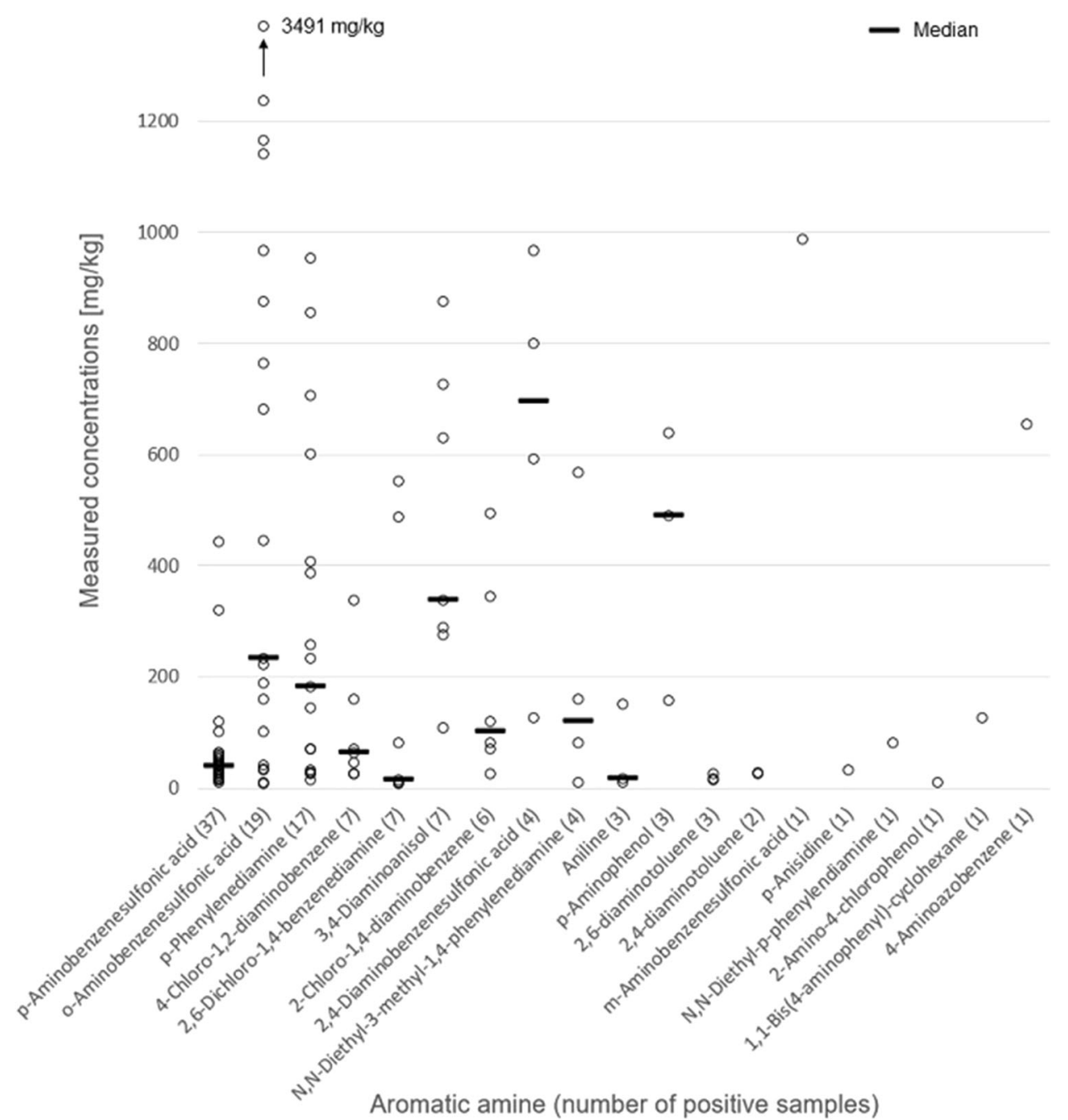

Aromatic amine (number of positive samples)

2. the substance could result from impurities or the presence of secondary synthesis products in the textile dye, or

3. a possible side reaction of the dyes with the reagent dithionite may have occurred.

According to the obtained information for one sample, an azo dye containing a "sulfo para base ester" moiety (CAS 42986-22-1) was used. This structure is relatively close to $o$-aminobenzenesulfonic acid. It has been shown that the formation of the forbidden AAs by a different path other than azo bond cleavage is minimized with the used reduction conditions, without being completely excluded for some amines findings below $30 \mathrm{mg} / \mathrm{kg}$ (Schneider 1997). These observations were made for regulated AAs. However, to our knowledge, no data is available in the literature for the non-regulated AAs analyzed in this study.

p-Aminobenzenesulfonic acid (CAS 121-57-3) was the most frequently detected AA with 37 positive samples. It was measured in $70 \%$ of the black cellulose-based textiles, compared to $30 \%$ and $20 \%$ for the blue and red dyed, respectively. Except for three samples with concentrations ranging from 100 to $442 \mathrm{mg} / \mathrm{kg}$, the measured concentrations of $p$-aminobenzenesulfonic acid were relatively low: $73 \%$ of positive results were below $45 \mathrm{mg} / \mathrm{kg}$ (Fig. 3).

For the six cellulose based samples for which dyestuff information was provided by the companies, Reactive Black 5 (either with CAS 17095-28-8 or 12225-25-1) was mentioned. It was possible to get the full information for four samples with $p$-aminobenzenesulfonic acid in concentrations from 29 to $38 \mathrm{mg} / \mathrm{kg}$. However, none of the dyes contained $p$-aminobenzenesulfonic acid. The low concentrations found in the samples suggest that $p$ aminobenzenesulfonic acid may be an impurity, or a reaction product with dithionite of the main dye or a part of it; for example "para base ester" (CAS 2494-89-5), which is structurally similar to $p$-aminobenzenesulfonic acid. The structure of Reactive Black 5 with the CAS 12225-25-1 is identical to $17095-28-8$ according to some sources, but differs according to others. The other proposed structure does not contain a "para base ester". However, the structure "para base ester" seems to appear frequently in 
reactive dyes. Given the generally low measured concentrations of $p$-aminobenzenesulfonic acid, the previously formulated hypothesises might apply for all positive samples of the survey, except those with high contents.

\subsection{Outcome and limitations of the study}

Our results show that a substantial number of colored textiles contained non-regulated AAs of toxicological concern, or got released after extraction and reductive cleavage. Indeed, different causes for the occurrence of non-regulated AAs may be considered, including the presence of free amines in textiles due to contamination or impurities of the dyes. The maximum measured concentrations were strikingly high $(>1000 \mathrm{mg} / \mathrm{kg})$. There is an obvious need to assess consumer health risks for these nonregulated AAs and to fill the gap in the regulation of clothing textiles. For a complete risk assessment, some other parameters have to be taken into account, like the release of the dyestuffs. A decisive factor in the release of dyestuffs is the way in which they adhere to the textile fibers and how they are bound. The release depends on the respective substance-fiber system and the pre-treatment of the fiber (Friedlipartner 2009). Other parameters to consider for a risk assessment are the cleavage of the azo bonds by human skin bacteria and the dermal absorption of the AAs (Brüschweiler and Merlot 2017).

Finally, some substances need further toxicological evaluation to diminish the uncertainty in their toxicological profile. For example, the mutagenic property of $o$ aminobenzenesulfonic acid was found twice to be weakly positive and once negative in Ames tests (NTP Rep 1986; Zeiger et al. 1988; ETAD 1981; as cited by Jung et al. 1992). Due to the high concentrations and the high number of positive samples in textiles found in this survey, the genotoxicity of $o$-aminobenzenesulfonic acid should be clarified in more detail by weight-of evidence approach.

\section{Conclusion}

In this study, AAs of toxicological concern were analyzed in 150 textile samples from cloth with direct skin contact bought on the Swiss market. AAs suspected of being mutagenic were included in this survey. Such AAs could be detected, after reductive cleavage of the azo groups of the textile dyes, in relevant concentrations $(>30 \mathrm{mg} / \mathrm{kg})$ in $25 \%$ of the analyzed samples, including potential derivates of nitro compounds. However, the analytical method used does not allow to distinguish between the nitro compound and its reduction derivate, bearing the corresponding amine moiety was cleaved off of the azo dye. However, several sources suggest that nitro compounds are used in polyester textiles. Finally, this survey clearly shows that a substantial percentage of azo dyes used in today's clothing textiles consists of hazardous AAs.

Acknowledgements This study was sponsored by the Federal Food Safety and Veterinary Office (FSVO), Berne, Switzerland (ARAMIS project number 17AA). Patrick Reber is highly acknowledged for purchasing the cloths, Daniel Anderson for the English proof reading and the Allchem team of the Official Food Control Authority of the Canton of Berne, Switzerland, for the daily collaboration.

\section{Compliance with ethical standards}

Conflict of interest The authors declare that they have no conflict of interest.

Open Access This article is distributed under the terms of the Creative Commons Attribution 4.0 International License (http://creative commons.org/licenses/by/4.0/), which permits unrestricted use, distribution, and reproduction in any medium, provided you give appropriate credit to the original author(s) and the source, provide a link to the Creative Commons license, and indicate if changes were made.

\section{References}

ANSES (Agence nationale de sécurité sanitaire alimentation, environnement, travail) (2018) Evaluation des effets sensibilisants ou irritants cutanés des substances chimiques présentes dans les articles chaussants et textiles d'habillement (Avis de l'Anses, rapport d'expertise collective)

BGFA (Forschungsinstitut für die Arbeitsmedizin der Deutschen Gesetzlichen Unfallversicherung (2009) Azofarbmittel und deren Hautgängigkeit beim Menschen. Literaturstudie. Institut der Ruhr-Universität Bochum. BGFA-Report 2. http://www.ipadguv.de/medien/ipa/publikationen/ipa-reporte/09-02-27_bgfareport2_azofarbstoffe.pdf. Accessed 15 Dec 2018

Brüschweiler BJ, Merlot C (2017) Azo dyes in clothing textiles can be cleaved into a series of mutagenic aromatic amines which are not regulated yet. Regul Toxicol Pharmacol 88:214-226

Brüschweiler BJ, Küng S, Bürgi D, Muralt L, Nyfeler E (2014) Identification of non-regulated amines of toxicological concern which can be cleaved from azo dyes used in clothing textiles. Regul Toxicol Pharmacol 69:263-272

CCRIS (Chemical Carcinogenesis Research Information System). Toxnet Toxicology Data Network, U.S. National Library of Medicine. https://toxnet.nlm.nih.gov/newtoxnet/ccris.htm. Accessed 15 Dec 2018

DIN (Deutsche Industrienorm) (2017a) DIN EN ISO 14362-1:2017, Textiles-Methods for the determination of certain aromatic amines derived from azo colorants-Part 1: detection of the use of certain azo colorants accessible with and without extracting the fibres (ISO 14362-1:2017). https://www.beuth.de/de/norm/ din-en-iso-14362-1/258681764

DIN (Deutsche Industrienorm) (2017b), DIN EN ISO 14362-3:2017, Textiles-Methods for the determination of certain aromatic amines derived from azo colorants-Part 3: detection of the use of certain azo colorants, which may release 4-aminoazobenzene (ISO 14362-3:2017). https://www.beuth.de/de/norm/din-en-iso$14362-3 / 258681813$

EC (European Commission) (2006) regulation (EC) No 1907/2006 of the European Parliament and of the Council concerning the 
registration, Evaluation, Authorisation and Restriction of Chemicals (REACH) https://eur-lex.europa.eu/legal-content/DE/TXT/ ?qid=1546616521857\&uri=CELEX:02006R1907-20181201. Accessed 15 Dec 2018

ECHA (European Chemical Agency) (2018) Information on chemicals by ECHA. https://echa.europa.eu/de/information-on-chemi cals/registered-substances. Accessed 15 Dec 2018

ETAD (Ecological and Toxicological Association of Dyes and Organic Pigments Manufacturers) (1981-1991). Internal reports of unpublished studies by ETAD member companies

FDHA (Federal Department of Home Affairs) (2005) Swiss Ordinance on Articles with Human Skin Contact (Verordnung über Gegenstände für den Schleimhaut-, Haut- und Haarkontakt sowie über Kerzen, Streichhölzer, Feuerzeuge und Scherzartikel) from 23 November 2005 (status on 1st Mai 2017). SR 817.023.41. https://www.admin.ch/opc/de/classified-compilation/20050181/ index.html. Accessed 15 Dec 2018

FriedliPartner (2009) Textilfarbstoffe: Inventar, Stoffdaten und Priorisierung verwendeter Substanzen. https://books.google.ch/ books/about/Textilfarbstoffe.html?id=-hNKygAACAAJ\&redir_ $\mathrm{esc}=\mathrm{y}$

Hunger K (ed) (2003) Industrial dyes, chemistry, properties, applications. WILEY-VCH, Weinheim

Jung R, Steinle D, Anliker R (1992) A compilation of genotoxicity and carcinogenicity data on aromatic aminosulphonic acids. Food Chem Toxicol 30:635-660
Kämpfer P, Crettaz S, Nussbaumer S, Scherer M, Krepich S, Deflorin O (2019) Quantitative determination of 58 aromatic amines and positional isomers in textiles by high-performance liquid chromatography with electrospray ionization tandem mass spectrometry. J Chromatogr A 1592:71-81

NTP Rep (National Toxicology Program Reports, U.S. Department of Health and Human Services) (1986) Chemical tests results for mutagenicity in Salmonella assay in FY 1985

Platzek T, Lang C, Grohmann G, Gi U-S, Baltes W (1999) Formation of a carcinogenic aromatic amine from an azo dye by human skin bacteria in vitro. Hum Exp Toxicol 18:552-559

Rawat D, Mishra V, Sharma RS (2016) Detoxification of azo dyes in the context of environmental processes. Chemosphere 155:591-605

Schneider G (1997) Verwendungsverbot bestimmter Azofarbstoffe für Bedarfsgegenstände: Analytik und Bewertung von Analysenergebnissen. Deutsche Lebensmittel-Rundschau, 93(3):69-74

Stingley RL, Zou W, Heinze TM, Chen H, Cerniglia CE (2010) Metabolism of azo dyes by human skin microbiota. J Med Microbiol 59:108-114

Zeiger E, Anderson B, Haworth S, Lawlor T, Mortelmans K (1988) Salmonella mutagenicity tests: IV. Results from the tesing of 300 chemicals. Environ Mol Mutagen 11:1-158

Publisher's Note Springer Nature remains neutral with regard to jurisdictional claims in published maps and institutional affiliations. 